\title{
Behavioural responses to different types of predators by sand goby Pomatoschistus minutus: an experimental study
}

\author{
Carin Magnhagen, Elisabet Forsgren
}

Department of Zoology, Uppsala University, Box 561, S-75122 Uppsala, Sweden

\begin{abstract}
Predation risk influenced the behaviour of Pomatoschistus minutus (Pisces) during both reproductive and non-reproductive seasons in aquarium experiments. Reproductive rate was the same with and without predators, but different types of anti-predator behaviour were seen in different treatments. When 'attacked' by a tern model, the fish burrowed in the sediment. However, when cod Gadus morhua was present in the tank, the gobies stayed on the sediment surface, forming groups. $P$. minutus did not discriminate between hungry and satiated cod, even though hungry cod ate more gobies. Individual P. minutus were often found close to the cod, irrespective of its hunger state, seemingly inspecting the predator.
\end{abstract}

\section{INTRODUCTION}

The risk of being eaten by a predator can affect the behaviour of an animal in several ways. Foraging rate may decrease (Dill 1983, Metcalfe et al. 1987, Magnhagen 1988), habitat utilization may switch (Werner et al. 1983, Gilliam \& Fraser 1987, Schlosser 1988), and reproductive behaviour may change (Endler 1987). Anti-predator mechanisms include morphological features such as spines, body armour (Dodson 1984, McLean \& Godin 1989) and crypsis (Pietrewicz \& Kamil 1981), as well as behavioural tactics such as fleeing (Winfield et al. 1983), hiding (Stein \& Magnusson 1976), and flocking (Pulliam \& Caraco 1984). Schooling fish have a number of antipredator advantages compared to solitary fish, such as more efficient predator detection and lower risk for the individual fish to be attacked (Magurran \& Pitcher 1987).

A marine benthic fish, the sand goby Pomatoschistus minutus is abundant in shallow soft-bottom areas along the Swedish coast. It lives solitarily and is preyed on by fish (Pihl 1982) and birds (Doornbos 1984). We performed aquarium experiments in order to study antipredator behaviour in $P$. minutus, exposed to piscine and model avian predators, to see whether their response differed between different types of threat, and whether they were able to discriminate between predators with different hunger levels.
In Pomatoschistus minutus, males exhibit parental care. They build nests under mussel shells which they cover with sand, leaving just a small entrance (Fonds 1973, Hesthagen 1977), attract females with a display, and then guard the eggs until hatching. The species reproduces from May to July. Nest building and courtship probably make male gobies conspicuous and hence more vulnerable to predation (Potts 1984). It therefore seems possible that they can assess predation risk and adjust their behaviour accordingly. However, $P$. minutus was previously found not to change its reproductive rate in the presence of a predator (Magnhagen 1990). In those experiments, predation risk was simulated, using a cod - visible to the gobies but prevented from catching them. In our study predation risk was intensified, with cod and gobies interacting physically. Since $P$. minutus can be heavily preyed on by sea birds (Doornbos 1984, Kai Lindström pers. comm.), their response to a tern model was also studied.

\section{METHODS}

Experiments were carried out at Klubbans Biological Station, Fiskebäckskil, on the west coast of Sweden $\left(58^{\circ} 15^{\prime} \mathrm{N}, 11^{\circ} 28^{\prime} \mathrm{E}\right)$. Pomatoschistus minutus were caught with a hand-trawl at water depths $\leqslant 1 \mathrm{~m}$ in the vicinity of the laboratory and brought to the laboratory, 
kept in storage aquaria, and fed once a day with mussel meat (Mytilus edulis). Seawater (ca $30 \% \mathrm{~S}$ and 10 to $20^{\circ} \mathrm{C}$ ) was continuously renewed, both in storage aquaria and experimental tanks.

Different types of predators. Experiments were carried out in May and June 1989. In the evening 6 male Pomatoschistus minutus were put into each of 6 glassfibre tanks with a bottom area of $2 \mathrm{~m}^{2}$ (1800 l). Since tanks were placed outside, light conditions were natural. Bottom sediment ( $\mathrm{ca} 3 \mathrm{~cm}$ ) was taken from the natural habitat of $P$. minutus; it contained prey such as Corophium volutator, Nereis diversicolor and harpacticoid copepods. Clay flower pots (diameter $6 \mathrm{~cm}$, depth $6 \mathrm{~cm}$ ) cut in halves were provided as nest material, 6 in each tank. Six gravid females were kept in a cylindrical net enclosure with a bottom area of $17 \mathrm{dm}^{2}$ and a water depth of $60 \mathrm{~cm}$, in the middle of each fish tank, to encourage nest building by the males. The following morning at 09:00 $\mathrm{h}$, females, hitherto caged, were released into the tank. Number of nests per tank were then $1.8 \pm 1.2$. Each of the 6 tanks was assigned to one of the following 3 treatments:

(1) Bird predation risk: A model tern made of masonite was painted to mimic a common tern Sterna hirundo, common in the area. The tern was flown over the fish tank once every half hour during the light hours, except between 04:00 and 07:00 h, when the frequency was $1 \mathrm{~h}^{-1}$. 'Flying' was simulated by suspending the bird from a fine nylon string and letting it glide from one end of the tank to the other on the stretched out string. On each occasion the bird was flown 2 to 4 times in rapid sequence. Some of these times, at random, the nylon string was slackened which made the bird dip into the water, simulating attack.

(2) Fish predation risk: A Gadus morhua (body length 20 to $30 \mathrm{~cm}$ ) was placed into the fish tank. The cod had been fed with mussel meat (Mytilus edulis) the previous evening, to minimize the number of gobies eaten. Several individual cod were used, randomly chosen from a storage tank

(3) Control: No predation risk, but with the gobies being observed as in the experimental treatments (see below).

By adding females and predators after some nests had already been built, it was possible to study the response to predation risk in terms of both female and male reproductive behaviour. Observations were made by eye 5 times during the light hours with at least $2 \mathrm{~h}$ between observations. Pomatoschistus minutus can exhibit several types of behaviour in response to threat: burrowing into the sediment, hiding in the pots, fleeing, or group forming. We recorded the number of visible fish, and fish closer to each other than $15 \mathrm{~cm}$, as well as group sizes (number of fish in separate groups with individuals closer to each other than $15 \mathrm{~cm}$ ). In the bird treatment, the number of visible fish was counted both before and directly after model-flying. The same person observed all tanks on each particular occasion in an attempt to make treatments comparable. We also occasionally made observations together, using a small scaled grid $(25 \times 15 \mathrm{~cm})$ put on the bottom of the tank, to compare with the distances between individuals.

Experiments were terminated after $24 \mathrm{~h}$; at 09:00 h, nests were checked for eggs, and fish from the predation tank were counted to determine the number of gobies eaten by the cod. Sixteen replicates of each treatment were made.

There were no significant size differences in fish used for different treatments (ANOVA; $F_{2,558}=0.64$, NS). Mean body length was $50.6 \pm 6.8 \mathrm{~mm}(\mathrm{n}=561)$.

Predators with different hunger levels. This experiment was carried out in the middle of July, after the reproductive period of Pomatoschistus minutus. The tanks used were the same as in the previous experiment. Six male and 6 female $P$. minutus were placed into the tanks at 10:00 h. Observations were made 9 to 13 times during the first day, counting the number of visible fish and the number of fish in groups. At 09:00 h the following morning a cod was introduced into the tank, and the same observations as the day before were made. We also recorded the distance between the cod and the closest goby. The cod was removed in the evening, and the remaining gobies in the tanks counted. The cod used in the experiments had either been starved for $1 \mathrm{wk}$ or fed regularly (mussel meat or dead fish). Six replicates with hungry and 7 with fed cod were made. No size differences between fish in different treatments were found ( $t=0.1$, df $=139$, NS). Mean body length was $51.6 \pm 5.4 \mathrm{~mm}(\mathrm{n}=131)$.

Statistical methods. For each replicate the median value of the repeated observations was used for statistical testing. Data sets were tested for normality using the Kolmogorov-Smirnov one-sample test. Since data distributions did not significantly differ from normal, parametric tests could be used. Where ANOVA showed an overall significant difference, Scheffe's method was used to compare the means, when there were more than 2 different treatments, as recommended by Day \& Quinn (1989). Furthermore, ANCOVA was used for testing differences between treatments, adjusting for differences in the number of fish eaten or the number of fish visible.

\section{RESULTS}

\section{Different types of predator}

There was no significant difference between treatments in the number of nests built before manipulations started (ANOVA; $F_{2.44}=1.6, N_{\text {i }}$ Table 1). How- 
Table 1 Pomatoschistus minutus. Number of nests $( \pm S D)$ in tanks subjected to 2 different treatments. Nests were counted at start and end and nests with eggs were recorded at the end of each experiment. Tanks contained 12 fish (sex ratio $1: 1$ ); 16 replicates of each treatment were run

\begin{tabular}{|lccc|}
\hline Treatment & \multicolumn{2}{c}{ No. of nests } & No. of nests \\
& Start & End & with eggs \\
\hline Bird predator & $2.3 \pm 1.5$ & $2.9 \pm 1.2$ & $1.9 \pm 0.7$ \\
Fish predator & $1.5 \pm 1.0$ & $1.8 \pm 1.1$ & $1.2 \pm 0.7$ \\
Control & $1.7 \pm 1.1$ & $2.4 \pm 1.5$ & $1.5 \pm 0.7$ \\
\hline
\end{tabular}

ever, at the end of the experiment there were more nests in the bird treatment compared to the fish treatment $\left(F_{2,44}=3.3, p<0.05\right.$, Scheffe $)$ but the number of nests in the bird treatment was not different from that in the control (Scheffe, NS). This was caused by the slightly higher number of nests at the beginning of the experiment. The number of nests built during the experiment did not differ $\left(F_{2,44}=1.1\right.$, NS). The number of nests with eggs was lower in the fish treatment $\left(F_{2,44}=3.2, \mathrm{p}<0.05\right.$, Table 1$)$. However, after adjusting - in a covariance analysis - for number of females eaten by the cod in the separate replicates, no difference was found (ANCOVA; $F_{3.43}=2.1$, NS).

The mean number of fish seen in the tanks was calculated using the median of all observations for each replicate. In the bird predator replicate the number of fish seen decreased directly after flying the bird model compared to just before (paired $t$-test; $t=5.2, \mathrm{df}=12$, $p<0.001)$. When comparing treatments there was a highly significant difference in the number of visible fish, when using values both before flying (ANOVA; $\left.F_{2.44}=6.4, \mathrm{p}<0.01\right)$ and after $\left(F_{2,44}=26.6, \mathrm{p}<0.001\right)$. The highest number was found in the fish predator treatment and the lowest in the bird treatment, with the bird treatment differing significantly from the fish predator treatment and the control, which did not differ significantly from each other (Scheffe, $p<0.05$, Fig. 1a). Furthermore, the number of fish closer than 15 $\mathrm{cm}$ from another fish was significantly higher in the fish treatment compared to the other treatments (ANOVA; $F_{2,44}=15.0, p<0.001$, Scheffe $\mathrm{p}<0.05$ ) (Fig. 1b); however, there were no differences between bird predator treatment and the control. After adjusting for the total number of fish visible there was still a significant difference (ANCOVA; $F_{3,43}=6.9, p<0.01$ ). This difference was found despite the fact that gobies were eaten during this treatment thus strengthening the result.

When comparing maximum group size (number of fish in groups with less than $15 \mathrm{~cm}$ between individuals) in each replicate, the fish predator treatment resulted in a larger group size than the bird treatment and the control $\left(F_{2,44}=24.8, \mathrm{p}<0.001\right.$, Scheffe; Fig. $\left.1 c\right)$.
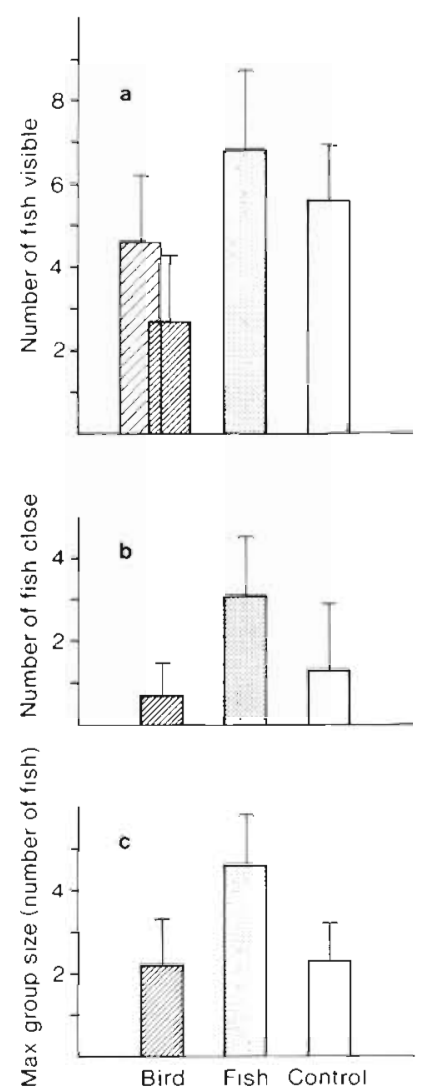

Fig. 1. Pomatoschistus minutus. Tank-held fish were exposed to bird predation risk and fish predation risk (for each treatment 16 replicates). Each tank contained 12 fish (sex ratio $1: 1$ ). (a) Number of gobies visible; during bird predation fish were counted both before (widely hatched) and after (densely hatched) tern model flying. (b) Number of gobies closer to each other than $15 \mathrm{~cm}$. Means in (a) and (b) calculated from median values of all observations in each replicate. (c) Maximum number of gobies in one group with individuals closer to each other than $15 \mathrm{~cm}$. Means in (c) were calculated using the highest number of fish seen together in each replicate. Error bars: SD

The number of Pomatoschistus minutus eaten by the cod in each replicate was $4.1 \pm 3.9$ (range 0 to 12 ). The same number of females $(2.0 \pm 2.4)$ and males $(2.6 \pm 3.7)$ was eaten $(t$-test; $t=0.5, \mathrm{df}=34, \mathrm{NS})$. The gobies eaten did not differ in body size from the survivors $(t=0.8, \mathrm{df}=190, \mathrm{NS})$.

\section{Predators with different hunger levels}

The number of gobies eaten per replicate differed between hungry $(6.2 \pm 4.3)$ and fed $(0.1 \pm 0.4) \mathrm{cod}(t$ test; $t=3.4$, df $=5.1, p<0.02$ ). The body length of the individuals eaten did not differ from that of the survivors $(t=0.5, \mathrm{df}=129$, NS).

The difference in number of gobies visible before 
and after the cod was introduced, calculated from medians of all observations for each replicate, pooling the treatments, was not significant (paired $t$-test $t_{i} t=$ 2.18, $\mathrm{df}=12, \mathrm{p}=0.05$ ), but with a tendency for numbers of fish to be slightly lower in the presence of the cod $(5.7 \pm 3.2)$ than in their absence $(7.8 \pm 1.0)$, due to gabies being successively eaten. In spite of this, the number of fish closer to each other than $15 \mathrm{~cm}$ increased in the presence of cod (4.2 \pm 2.5$)$ compared to the situation before cod introduction $(2.3 \pm 1.1)$ (paired $t$-test; $t=2.23, \mathrm{df}=12, \mathrm{p}<0.05$ ).

When comparing treatments with hungry and fed cod, adjusting for number of fish eaten in a covariance analysis, no significant difference was found neither in number of gobies visible (ANCOVA; $F_{2,10}=3.8, \mathrm{NS}_{\text {; }}$ Fig. 2a), or number of fish closer than $15 \mathrm{~cm}$ to another individual $\left(F_{2,10}=4.7\right.$. NS; Fig. $\left.2 b\right)$. Maximum group size in the separate replicates (see previous experiment for explanation) did not differ between treatments with hungry or fed cod (ANOVA; $F_{1,11}=3.7, \mathrm{NS}$ ) (Fig. 2c)
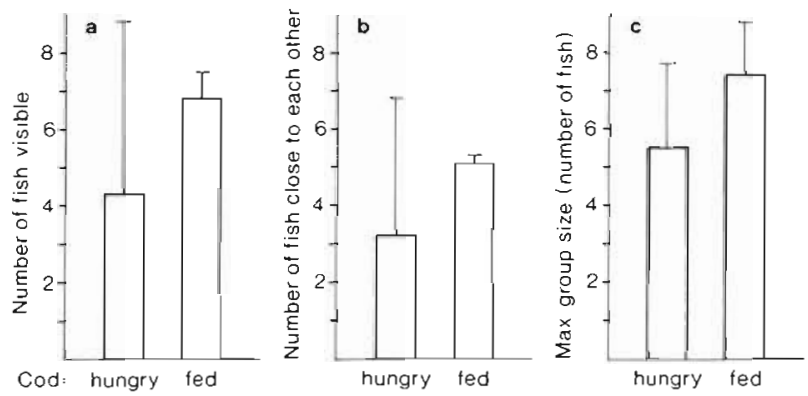

Fig. 2. Pomatoschistus minutus. Fish kept in tanks together with either a hungry or a fed cod. (a) Number of gobies visible. (b) Number of gobies closer to each other than $15 \mathrm{~cm}$. Means in (a) and (b) were calculated from median values of all observations in each replicate. (c) Maximum number of gobies in one group with individuals closer to each other than $15 \mathrm{~cm}$. Means in (c) were calculated using the highest number of fish seen together in each replicate. Tanks contained 12 gobies with a sex ratio of $1 \cdot 1 ; 6$ replicates with hungry, 7 with fed cod. Error bars: SD

The median closest distances between an individual Pomatoschistus minutus and the cod was $110.0 \pm$ $45.6 \mathrm{~cm}$ in the presence of a hungry cod and $85.7 \pm 53.4 \mathrm{~cm}$ of a fed cod (ANOVA; $F_{1,11}=0.20, \mathrm{NS}$ ) One goby was often observed close to the predator $(\leq 30 \mathrm{~cm})$, seemingly 'inspecting' it. The number of times per replicate that a goby was found closer than 30 $\mathrm{cm}$ from the cod was not significantly different between treatments $(1.53 \pm 1.0$, hungry cod, $2.7 \pm 0.9$, fed cod, t-test; $t=2.19$, df $=12, p=0.05)$. A tendency for $a$ lower value in the hungry cod replicates was probably due to the lower number of fish present at the end of the experiment.

\section{DISCUSSION}

The observed reproductive behaviour of Pomatoschistus minutus was not affected by experimentally altered predation exposure. Neither the number of nests built nor the number of nests containing eggs differed between treatments. These results support those obtained in a previous study (Magnhagen 1990) in which $P$. minutus did not change its reproductive rate in the presence of a cod kept behind a glass wall. An individual $P$. minutus has only 1 breeding season in its life-time, and may have to take some risks in order to get any offspring at all. In contrast, the closely related black goby Gobius niger, which is more long-lived and has several breeding seasons, was found to refrain from breeding under experimentally altered predation risk when young ( 2 to $3 \mathrm{yr}$ ), but spawned readily when older ( 4 to $5 \mathrm{yr}$ ) in the presence of a cod (Magnhagen 1990).

Even though no response to predation risk was found in the reproductive behaviour of Pomatoschistus minutus, depending on type of threat, the gobies showed different anti-predator responses. They burrowed in the sediment in the presence of the avian predator; in the presence of cod, they stayed on the sediment surface, and formed groups.

One difference between the piscine and the avian predator was that the cod was present throughout the experiment, while the bird model appeared intermittently and thus represented an unpredictable risk, as in nature. In the presence of a sudden threat the fastest anti-predator behaviour probably is to burrow into the sediment. According to Pitcher et al. (1988) minnows Phoxinus phoxinus sought cover in the weed after an 'attack' by a model kingfisher and stayed there feeding even after $6 \mathrm{~h}$. The number of visible gobies was lower in the bird predator treatment compared to the fish predator treatment and the control both before and after each attack, but with only $30 \mathrm{~min}$ between attacks, they might not have completely recovered from the previous attack.

In the presence of the cod, conflicting demands of foraging, reproducing and predator avoidance might have affected the behaviour of the gobies. Pomatoschistus minutus have previously been found to decrease food intake in the presence of cod (Magnhagen 1988). Group formation probably increases the total vigilance. Similarly, flock size has been found to increase in yellow-eyed juncos Junco phaeonotus in the presence of a predator (Caraco et al. 1980), which was explained by the 'many eyes' hypothesis, i.e. that flocking allows individuals to spend less time scanning for predators and more time feeding. This has also been observed in other birds such as quelea Quelea quelea (Lazarus 1979) and starling Sturnus vulgaris (Powell 
1974). In the minnow Phoxinus phoxinus large shoals were found to detect a predator faster, and to continue feeding for longer time when a predator was approaching compared to smaller shoals (Magurran et al. 1985). Furthermore, the probability of any particular individual falling victim to the predator probably decreases in a flock, according to the dilution effect (Pulliam \& Caraco 1984).

If there is a cost of predator avoidance such as a reduced foraging rate, it would be adaptive for prey to be able to discriminate between hungry and satiated predators. This ability has been found to exist, for example, in the guppy Poecilia reticulata (Licht 1989). In Pomatoschistus minutus we found no behavioural difference in the presence of hungry versus satiated cod, even though the risk differed in the 2 treatments, judging from the number of gobies eaten.

Predator inspection is a common phenomenon in fish (Giles \& Huntingford 1984, Pitcher et al. 1986, Milinski 1987, Dugatkin 1988) as well as in other animals, e.g. birds (Curio 1976, Lazarus 1979). During predator encounters small groups of fish leave their shoal, approach the predator, halt and return. While Pomatoschistus minutus is not a shoaling species, individuals were found close together in the presence of the cod. Also, it was frequently seen that one fish swam close to the cod as if inspecting it. Predator inspection is regarded as a cooperative behaviour in shoaling species, with information transferred within the group (Dugatkin 1988). However, individual differences in boldness have been recorded, for example in the threespined stickleback Gasterosteus aculeatus (Huntingford 1976. Milinski 1987) and the minnow Phoxinus phoxinus (Magurran 1986). The reason for individual $P$. minutus to approach the predator is not known, but as a basically solitary species, individual differences in boldness are more likely to play a role than is cooperation between individuals. The seemingly dangerous approaching behaviour may offer an advantage to the inspecting individual, in solitary as well as shoaling species, in terms of obtaining more information and/or showing the predator that it has been detected.

Acknowledgements. The study was supported financially by the Swedish Natural Science Research Council and Magnus Bergvalls Stiftelse (C.M.) and the Royal Swedish Academy of Science (E.F.). We thank Anders Berglund, Anders P. Moller and Staffan Ulfstrand for valuable comments on the manuscript, and Kristina Forsgren, Lotta Kvarnemo, and Gunilla Rosenquist (especially for early mornings) for flying the birds, and helping with feeding and fish collection.

\section{LITERATURE CITED}

Caraco, T., Martindale, S., Pulliam, H. R. (1980). Avian flocking in the presence of a predator. Nature, Lond. 285: $400-401$
Curio, E. (1976). The ethology of predation. Springer-Verlag, Berlin

Day, R., Quinn, G. P. (1989). Comparisons of treatments after an analysis of variance in ecology. Ecol. Monogr. 59: $433-463$

Dill, L. M. (1983). Adaptive flexibility in the foraging behaviour of fishes. Can. J. Fish. Aquat. Sci. 40: 398-408

Dodson, S. I. (1984). Predation on Heterocope septentrionalis on two species of Daphnia: morphological defenses and their cost. Ecology 65: 1249-1257

Doornbos, G. (1984). Piscivorous birds on the saline lake Grevelingen, The Netherlands: abundance, prey selection and annual food consumption. Neth. J. Sea Res. 18: $457-479$

Dugatkin, L. A. (1988). Do guppies play TIT FOR TAT during predator inspection visits? Behav. Ecol. Sociobiol. 23: 395-399

Endler, J. A. (1987). Predation, light intensity and courtship behaviour in Poecilia reticulata (Pisces: Poeciliidae). Anim. Behav. 35: 1376-1385

Fonds, M. (1973). Sand gobies in the Dutch Wadden Sea (Pomatoschistus, Gobiidae, Pisces). Neth. J. Sea Res. 6: $417-478$

Giles, N., Huntingford, F. A. (1984). Predation risk and interpopulation variation in anti-predator behaviour in the three-spined stickleback, Gasterosteus aculeatus L. Anim. Behav. 32: 264-275

Gilliam, J. F., Fraser, D. F. (1987). Habitat selection under predation hazard: test of a model with foraging minnows. Ecology 68: 1856-1862

Hesthagen, I. H. (1977). Migrations, breeding, and growth in Pomatoschistus minutus (Pallas) (Pisces, Gobiidae) in Oslofjorden, Norway. Sarsia 63: 17-26

Huntingford, F. A. (1976). The relationship between antipredator behaviour and aggression among conspecifics in the three-spined stickleback, Gasterosteus aculeatus. Anim. Behav. 24: 245-260

Lazarus, J. (1979). The early warning function of flocking in birds: an experimental study with captive quela. Anim. Behav. 27: 855-865

Licht, T (1989). Discriminating between hungry and satiated predators: the response of guppies (Poecilia reticulata) from high and low predation sites. Ethology 82: 238-243

Magurran, A. E. (1986). Predator inspection behaviour in minnow shoals: differences between populations and individuals. Behav. Ecol. Sociobiol. 19: 267-273

Magurran, A. E., Oulton, W. J., Pitcher, T J. (1985). Vigilant behaviour and shoal size in minnows. Z. Tierpsychol. 67 : $167-178$

Magurran, A. E., Pitcher, T J. (1987). Provenance, shoal size and the sociobiology of predator-evasion behavior in minnow shoals. Proc. R. Soc. Lond. B 229: 439-465

Magnhagen, C. (1988). Changes in foraging as a response to predation risk in two gobiid fish species, Pomatoschistus minutus and Gobius niger. Mar. Ecol. Prog. Ser. 40: $21-26$

Magnhagen, C. (1990). Reproduction under predation risk in the sand goby, Pomatoschistus minutus and the black goby, Gobius niger: the effect of age and longevity. Behav. Ecol. Sociobiol. 26: 331-335

McLean, E. B., Godin, J.-G. J. (1989). Distance to cover and fleeing from predators in fish with different amounts of defensive armour. Oikos 55: 281-290

Metcalfe, N. B., Huntingford, F. A., Thorpe, J. E. (1987). The influence of predation risk on the feeding motivation and foraging strategy of juvenile Atlantic salmon. Anim. Behav. 35: 901-911 
Milinski, M. (1987). TIT FOR TAT in sticklebacks and the evolution of cooperation. Nature, Lond. 325: 433-437

Pietrewicz, F. A., Kamil, A. C. (1981). Search images and the detection of cryptic prey: an operant approach. In: Kamil, A. C., Sargent, T. D. (eds.) Foraging behavior: ecological, ethological and psychological approaches. Garland STPM press, New York, p. 311-332

Pihl, L. (1982). Food intake of young cod and flounder in a shallow bay on the Swedish west coast. Neth. J. Sea Res. 15: $419-432$

Pitcher, T. J., Green, D. A., Magurran, A. E. (1986). Dicing with death: predator inspection behaviour in minnow shoals. J. Fish Biol. 28: 438-448

Pitcher, T. J., Lang, S. H., Turner, J. A. (1988). A risk-balancing trade off between foraging rewards and predation hazard in a shoaling fish. Behav. Ecol. Sociobiol. 22: $225-228$

Potts, G. W (1984). Parental behaviour in temperate marine teleosts with special reference to the development of nest structures. In: Potts, G. W., Wootton, R. J. (eds.) Fish reproduction: strategies and tactics. Academic Press, London, p. 223-244

This article was submitted to the editor
Powell, G. V N. (1974). Experimental analysis of the social value of flocking by starlings (Stumus vulgaris) in relation to predation and foraging. Anim. Behav. 22 501-505

Pulliam, H. R, Caraco, T (1984). Living in groups: is there an optimal group size. In: Krebs, J. R., Davies, N. B. (eds.) Behavioural ecology: an evolutionary approach, 2 nd edn. Blackwell, Oxford, p. 122-147

Schlosser, J. J. (1988). Predation risk and habitat selection by two size classes of a stream cyprinid: experimental test of a hypothesis. Oikos 52: $36-40$

Stein, R. A., Magnusson, J. J. (1976). Behavioral response of crayfish to a fish predator. Ecology 57: 751-761

Werner, E. E., Mittelbach, G. G., Hall, D. J., Gilliam, J. F. (1983). Experimental test of optimal habitat use in fish: the role of relative habitat profitability. Ecology 64 $1525-1539$

Winfield, I. J., Peirson, G., Cryer, M., Townsend, C. R. (1983). The behavioural basis of prey selection by underyearling bream (Abramis brama (L.)) and roach (Rutilus rutilus (L.)). Freshwater Biology 13: 139-149

Manuscript first received: March 20, 1990

Revised version accepted: November 8, 1990 